\section{Reviewer awards}

\author{
Ruth E Malone
}

As another new year approaches, it is time to take stock of our priorities and renew our commitments to them. As a journal editorial team, it is also a time to recognize the essential role played by the reviewers we count upon to help us keep the journal timely, relevant to tobacco policy and population health on a global level, and known as a publisher of the very best science and policy analysis in our field. The editors simply could not do our jobs without the steadfast participation of an enormous community of dedicated reviewers, who freely contribute their valuable time to help in the peer review process. We appreciate each and every one of them.

While peer review is not a perfect process, each member of the senior editorial team can testify to its importance in improving the contribution of many papers each year. Reviewers notice things that authors fail to see because they are so close to the work. Sometimes they help authors understand and articulate the larger implications of their work; other times they gently point out that the authors have gone beyond their data and must scale back overenthusiastic claims. Sometimes they help authors restructure their papers so the points are clearer; other times they propose entirely new analyses the authors had not thought to do with their data. Sometimes editors think a study sounds new and important, only to have astute reviewers point out that many similar studies have already been published. Sometimes the opposite happens, and editors think a paper is a well-enough done but rather modest contribution, only to have reviewers see in it something quite novel that advances the science or opens up new avenues for study.

Last year, we inaugurated a tradition of honouring Reviewers of the Year.

Correspondence to Department of Social and Behavioral Sciences, School of Nursing, University of California San Francisco, San Francisco, California, US; ruth.malone@ucsf.edu
Nominated by the senior editors, these reviewers often go above and beyond the norm. Too frequently unrecognized and taken for granted, good reviewers are a journal's gold. We are very happy to specially recognize the following reviewers this year, selected from a large pool of nominees, all of whom were well-qualified to be honoured as well. In alphabetical order, this year's Reviewers of the year are:

Leonie Brose: Dr. Brose, a health psychologist, has been very generous in completing at least seven reviews during the past year for Tobacco Control. Further, as senior editor and nominator Coral Gartner noted, her reviews are very detailed and have led to substantial improvements in manuscripts. But the kicker: She has never been late with a review.

Suzan Burton: A professor of marketing in Australia, Dr. Burton completed several reviews for the journal last year, and her reviews are characterized as "critical, compelling, and on time!" (You may notice that editors weight the latter characteristic heavily in selection).

Cristine Delnevo: Dr. Delnevo, who leads a department of health education and behavior at Rutgers University, is a workhorse reviewer for the journal who this year took on an additional role as guest editor for a supplement on flavours in tobacco products. The supplement was on a tight timeline and Dr. Delnevo managed the entire review process as a first-time guest editor with efficiency, rigour, and good humour.

James Thrasher: Dr. Thrasher's work in low and middle income countries no doubt informs the sensitivity with which he reviews and helps move along papers from low and middle income countries authors. As we have noted before in these pages, such authors are often disadvantaged by non-native English language skills and inexperience with preparing papers for scientific journals. Sometimes, reviewers simply refuse to tackle papers with such problems. Dr. Thrasher accepts these invitations and tries to help authors.

Francis Thompson: As executive director of the Framework Convention Alliance, Thompson is an expert in global tobacco control policy and advocacy, especially related to the history and implementation of the World Health Organisation Framework Convention on Tobacco Control. His insightful and strategic comments on papers have helped authors vastly improve contributions to the literature on this landmark treaty.

Corne van Walbeek: An economist based in South Africa, Dr. van Walbeek provides very detailed and thoughtful reviews for many economics submissions. $\mathrm{He}$ is also remarkably willing to carefully re-review a revised paper when he has provided comments on the first version. Given that our readership is so disciplinarily broad, the usefulness of the many important economics studies we publish depends heavily upon reviewers who understand the science as well as how to translate and position the work so it is useful for non-economists.

Our reviewer pool spans an incredibly wide range of expertise, and this is reflected in the contributions we publish, which range from small qualitative studies to multi-country research to theory and advocacy contributions. The common thread in it all is a focus on policy and population health. As editors, we are gratified to be the "curators" of the fine work produced by this collective expertise, including not only the expertise of scientists and researchers from multiple disciplines, but that of community and national advocates, lawyers, and program and policy leaders who also serve as reviewers. Thank you to everyone who helps with this process, and warm congratulations to this year's honorees!

Competing interests None declared.

Provenance and peer review Not commissioned; not peer reviewed.

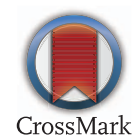

To cite Malone RE. Tob Control 2017;26:1.

Tob Control 2017;26:1.

doi:10.1136/tobaccocontrol-2016-053574 